\title{
Does a math problem in IPCC report climate change 2007: The physical science basis (AR4) compromise the science?
}

\section{Opinion}

It is not well known in scientific circles that incorrect mathematics was applied in estimating the radiative efficiency (RE) of carbon dioxide $\left(\mathrm{CO}_{2}\right)$ in section 2.10 .2 of Intergovernmental Panel on Climate Change (IPCC) Fourth Assessment Report (AR4) titled Climate Change 2007: The Physical Science Basis. ${ }^{1}$

The authors are interested in the $\mathrm{RE}$ of $\mathrm{CO}_{2}$ at a concentration of 378 parts per million by volume, ppmv. Unfortunately, there is no definition of RE in the Glossary to AR4. However, it appears RE is defined as the change in radiative forcing (RF) for a unit change in $\mathrm{CO} 2$ concentration. This is the slope of a line tangent to the curve of $\mathrm{RF}$ versus the $\mathrm{CO}_{2}$ concentration level.

The difference in RF between two concentrations of $\mathrm{CO}_{2}$ is defined in the IPCC Third Assessment Report (TAR) ${ }^{2}$ as a logarithmic function as in Equation (1):

$$
\Delta R F=5.35 \ln \left(C / C_{o}\right)
$$

Where $\triangle R F$ is the difference in radiative forcing, $\mathrm{C}$ is the higher concentration of $\mathrm{CO}_{2}$ and $\mathrm{Co}$ is the lower. The authors approximated the slope of the logarithmic curve at 378 ppmv by using a perturbation of 1 ppmv, i.e., where $\mathrm{C}=379$ ppmv and $\mathrm{C}_{\mathrm{o}}=378$ ppmv as in Equation (2):

$$
\Delta R E=5.35 \times \ln (379 / 378)=0.014135{W m^{-2}}^{-2 p m v^{-1}}
$$

The details of the perturbation method are given in footnote "b" on page 213 of AR4. The first derivative of the logarithmic curve, Equation (1), gives the slope of the logarithmic curve at any concentration. The slope, $\mathrm{RE}$, at $\mathrm{CO}_{2}$ concentration of $378 \mathrm{ppmv}$ is as shown in Equation (3):

$$
R E=5.35 / 378 p p m v=0.014153{W m^{-2}}^{p p m v^{-1}}
$$

The perturbation method came very close to the correct answer as it is only off by 0.0000187 ppmv or by $(0.0000187 / 0.014153)=$ $0.0132 \%$.

The perturbation method actually gives the average RE between that of 378 and 379 ppmv. For example

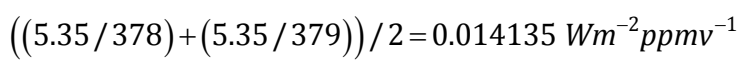

The fact that the mathematical logic is incorrect causes two problems:

a) The credibility of IPPC report AR4 is compromised because of the lack of knowledge of mathematics; in this case it is calculus. This error was not caught by any of the reviewers during the preparation of AR4. It raises the question as to whether or not there are other places in AR4 or other IPCC reports where there are errors in the mathematical logic.

\author{
Volume 2 Issue 4 - 2018

\begin{abstract}
H Douglas Lightfoot,' Orval A Mamer²
'Co-founder of the Lightfoot Institute, Canada ${ }^{2}$ Goodman Cancer Research Centre of McGill University, Canada
\end{abstract}

\begin{abstract}
Correspondence: $\mathrm{H}$ Douglas Lightfoot, Co-founder of the Lightfoot Institute, 8Watterson, Baie-D’Urfe, QC, H9X 3C2, Canada,Tel 5I4-457-5637, Email dlightfo@aei.ca
\end{abstract}

Received: July 27, 2018 | Published: August 09, 2018

b) Because the perturbation method is cumbersome and inaccurate, it is not easy to generate RE over large ranges of concentration. For example, the logarithmic curve of Equation (2) is only an approximation. By using the correct math it can be readily shown that the RE, or slope of the curve only becomes zero at infinity. Actually, for practical purposes RE becomes zero much earlier than infinity. Because the amount of infrared radiation (IR) is limited, as the concentration of $\mathrm{CO}_{2}$ increases there is less and less IR for each molecule to absorb. Thus, there is a practical physical limit to the amount of IR that can be absorbed by $\mathrm{CO}_{2}$ regardless of the concentration. ${ }^{3}$

Mathematics is of such importance to science that it is important to understand and verify the logic and its application.

\section{Acknowledgements}

None.

\section{Conflict of interest}

Author declares there is no conflict of interest.

\section{References}

1. Solomon S, Qin D, Manning M. IPCC Climate Change 2007: The Physical Science Basis. Contribution of Working Group I to the Fourth Assessment Report (AR4) of the Intergovernmental Panel on Climate Change. UK: Cambridge University Press; 2007. 213 p.

2. Houghton JT, Ding Y. Climate Change 2001. Working Group I: The Scientific Basis, Intergovernmental Panel on Climate Change, 2001, Third Assessment Report (TAR). USA: Cambridge University Press; 2001.

3. Lightfoot HD, Mamer OA. Calculation of atmospheric radiative forcing (warming effect) of carbon dioxide at any concentration. Energy \& Environment. 2014;25(8). 